\title{
Non-Keratinizing Epithelioma
}

National Cancer Institute

\section{Source}

National Cancer Institute. Non-Keratinizing Epithelioma. NCI Thesaurus. Code C84356.

An epithelioma characterized by the absence of keratin production. 